OPEN ACCESS

Edited by:

Mats Granlund,

Jönköping University, Sweden

Reviewed by:

Lan Yang,

The Education University of

Hong Kong, Hong Kong

Elizabeth Fraser Selkirk Hannah, University of Dundee, United Kingdom

*Correspondence:

Moritz Börnert-Ringleb moritz.boernert-ringleb@ ifs.uni-hannover.de

Specialty section:

This article was submitted to Special Educational Needs,

a section of the journal

Frontiers in Education

Received: 17 July 2020 Accepted: 06 November 2020 Published: 27 November 2020

Citation:

Börnert-Ringleb M, Westphal A Zaruba N, Gutmann F and Vock M (2020) The Relationship Between Attitudes Toward Inclusion, Beliefs About Teaching and Learning, and Subsequent Automatic Evaluations

Amongst Student Teachers.

Front. Educ. 5:584464.

doi: 10.3389/feduc.2020.584464

\section{The Relationship Between Attitudes Toward Inclusion, Beliefs About Teaching and Learning, and Subsequent Automatic Evaluations Amongst Student Teachers}

\author{
Moritz Börnert-Ringleb ${ }^{1 *}$, Andrea Westphal ${ }^{2}$, Nicole Zaruba ${ }^{2}$, Franziska Gutmann ${ }^{3}$ and \\ Miriam Vock ${ }^{2}$
}

${ }^{1}$ Institute of Special Education, Leibniz University Hannover, Hannover, Germany, ${ }^{2}$ Department of Educational Research, University of Potsdam, Potsdam, Germany, ${ }^{3}$ Department of Sport and Health Sciences, University of Potsdam, Potsdam, Germany

Teachers' attitudes toward inclusion are frequently cited as being an important predictor of how successfully a given inclusive school system is implemented. At the same time, beliefs about the nature of teaching and learning are discussed as a possible predictor of attitudes toward inclusion. However, more recent research emphasizes the need of considering implicit processes, such as automatic evaluations, when describing attitudes and beliefs. Previous evidence on the association of attitudes toward inclusion and beliefs about teaching and learning is solely based on explicit reports. Therefore, this study aims to examine the relationship between attitudes toward inclusion, beliefs about teaching and learning, and the subsequent automatic evaluations of pre-service teachers $(N=197)$. The results revealed differences between pre-service teachers' explicit attitudes/beliefs and their subsequent automatic evaluations. Differences in the relationship between attitudes toward inclusion and beliefs about teaching and learning occur when teachers focus either on explicit measures or automatic evaluations. These differences might be due to different facets of the same attitude object being represented. Relying solely on either explicit measures or automatic evaluations at the exclusion of the other might lead to erroneous assumptions about the relation of attitudes toward inclusion and beliefs about teaching and learning.

Keywords: inclusion, attitudes, teaching, automatic evaluation, beliefs, implicit

\section{INTRODUCTION}

Teachers' attitudes toward inclusion are frequently cited as being an important predictor of how successfully a given inclusive school system is implemented. Several studies have examined possible predictors of attitudes toward inclusion. It is supposed that teachers' attitudes have a major influence on their subsequent actions in practice (e.g., Jordan et al., 2009; Sharma and Sokal, 2016). Accordingly, negative attitudes toward inclusion represent obstacles in the successful implementation of inclusive practices.

At the same time, there is little consensus about what precisely is meant by attitudes. Pajares (1992) argues that different constructs (e.g., subjective theories, beliefs, and attitudes) are used 
synonymously. Most prominently, Eagly and Chaiken (2007) refer to attitudes as an "individual's propensity to evaluate a particular entity with some degree of favorability or unfavorability" (p. 583). Such evaluations comprise affective, cognitive, and behavioral components of responding (Eagly and Chaiken, 1998). These assumptions go hand in hand with the ideas of Ajzen and Fishbein (2005). According to their theory of planned behavior, behavioral intentions are explained by attitudes toward behavior, subjective norms, and perceived behavioral control.

However, in more recent research, explorations of attitudes differentiate between explicit and implicit attitudes in a more complex way (Eagly and Chaiken, 2007). This is in line with theoretical discussions about dual-process models (e.g., Gawronski and Bodenhausen, 2011; Evans and Stanovich, 2013). Such models argue that mental processes can be differentiated between automated and controlled processes (e.g., Gawronski and Creighton, 2013) and describe humans as continuous processors of information. According to a default-interventionist logic (e.g., Evans, 2007; Evans and Stanovich, 2013), automated processes generate fast default responses (Type 1 processes), which subsequently may be controlled and conscious reflected (Type 2 processes). When prompted with the idea of "inclusion," for example, a spontaneous affective "gut feeling" may arise that inclusion feels "good" or "bad." This gut feeling can be defined as an automatic evaluation and refers to the overall valence of activated "mental associations in memory" (e.g., Gawronski and Bodenhausen, 2011, p. 61). Such automatic evaluations are influenced by the "preexisting structure of associations in memory" (p. 62), as well as the context and configuration of presented stimuli. These automatic evaluations provide the basis for further conscious reflections (i.e., attitudes or beliefs), like the idea, for instance, that working in an inclusive setting can be personally beneficial. These reflective processes however set additional demands on cognitive and motivational processes. It is therefore possible that focusing spontaneously evoked, automatic evaluations on the concept of inclusion might be of particular interest for researchers as these evaluations provide the default mode for behavioral decisions, which can only be altered with enough time and cognitive resources. In contrast, explicit attitudes may be of higher relevance for predicting behaviors in situations which are under "volitional control" (Eagly and Chaiken, 2007, p. 593). Ajzen and Fishbein (2005) summarize that "their research on the prediction of behavior from intentions has shown that, as a general rule, when people have control over performance of a behavior, they tend to act in accordance with their intentions." (p. 192). In contrast, in situations with less control over behavior, the influence of intentions might be reduced. In such situations, implicit processes (such as automatic evaluations) might serve as a more direct predictor of behavior, "unless they are overridden by controlled processes" (Ajzen and Fishbein, 2005, p. 206).

To date, a vast body of research has addressed attitudes toward inclusion and has examined the possible outcomes as well as predictors of positive and negative attitudes (for an overview see Avramidis and Norwich, 2002; de Boer et al., 2011). However, very little is known about the interplay between automatic evaluations and attitudes toward inclusion and about the predictors of automatic evaluations toward inclusion. Previous studies tried to measure automatic evaluations toward inclusion (Lautenbach and Antoniewicz, 2018; Lüke and Grosche, 2018b) as well as toward children with special educational needs (Krischler and Pit-ten Cate, 2018) using different methods. These studies could only partially highlight (negative) correlations between automatic evaluations and explicit attitudes toward inclusion (Lautenbach and Antoniewicz, 2018). Moreover, Krischler and Pit-ten Cate (2018) highlighted differences between the automatic evaluations toward different types of special educational needs. However, no previous study compared patterns of associations between teacher-related variables, automatic evaluations and attitudes toward inclusion. The present study addresses this research gap with a multi-methodological approach.

\section{Relating Attitudes Toward Inclusion and Beliefs About Teaching and Learning}

Several studies have examined possible predictors of attitudes toward inclusion. Avramidis and Norwich (2002) differentiated between child-related, teacher-related, and educational environment-related variables. Despite this differentiation, a range of previous research emphasized teacher-related variables. de Boer et al. (2011) indicated that the teacher-related variables of gender, years of teaching experience, as well as experiences with inclusive education and training are all associated with more positive attitudes toward inclusion. Sharma and Sokal (2016) were able to show that positive attitudes toward inclusion are associated with higher teacher efficacy as well as less concerns about inclusive education. In addition to this, Avramidis and Norwich (2002) describe teachers' beliefs and socio-political views as variables associated with attitudes toward inclusion. In this context, the authors indicate that teacher beliefs are not only associated with attitudes toward inclusion but also with teaching behaviors.

In line with this argument, Jordan et al. (2009) indicated that effective inclusive teaching practices may depend on teachers' beliefs about the nature of disability and their perceived responsibilities when working with students with special educational needs. They highlighted that such beliefs may be part of a broader set of epistemological beliefs about the general nature of knowledge and learning.

The study found that teachers' beliefs that either focus on the "pathological characteristics of the learners" or "consider the learner in terms of how they best learn" (Jordan et al., 2009, p. 538) were associated with beliefs about ability as a fixed entity or as being "incremental and malleable" (Jordan et al., 2009 , p. 539). These beliefs are more commonly described as fixed and growths mindsets (e.g., Haimovitz and Dweck, 2017). Furthermore, they reported that the more teachers believe that ability is incrementally acquired, the less they favor transmissive teaching methods (Jordan et al., 2009).

In a similar vein, Silverman (2007) emphasized that positive attitudes toward inclusion are associated with high-level epistemological beliefs, which comprise beliefs 
about "knowledgeable but not omniscient authorities, with learners as active constructors of meaning" (Silverman, 2007, p. 43). In turn, Sheehy et al. (2019) focused on social constructivist and transmissive beliefs about learning within the framework of epistemological beliefs. They demonstrated that constructivist beliefs were more closely associated with positive attitudes toward inclusion than transmissive beliefs. Moreover, teachers in their study in inclusive classrooms showed higher levels of constructivist beliefs (Sheehy et al., 2019). These findings are of particular interest as they might be indicators of the underlying processes at work in the development of attitudes toward inclusion. Thus, in line with Jordan et al. (2009) results on beliefs about teachers' perceived responsibilities when working with students with special educational needs, teachers' attitudes toward inclusion might also be associated with broader sets of beliefs about teaching and learning processes, responsibilities, and the nature of knowledge.

\section{Beliefs About Teaching and Learning and Their Role in Inclusive Settings}

Beliefs about the nature of teaching and learning represent teachers' perspectives on how students should be taught. As mentioned above, these beliefs are often differentiated into traditional or transmissive beliefs vs. constructivist beliefs about teaching and learning (Handal, 2003; Chan and Elliott, 2004; Woolley et al., 2004; OECD, 2009; Voss et al., 2013; Fives et al., 2015).

Traditional or transmissive teaching beliefs describe teachercentered approaches and are associated with a behaviorist perspective on learning (Handal, 2003). That is to say, knowledge is directly transmitted to the students and therefore emphasizes the need of "isolated and independent learning" (Handal, 2003, p. 47). Consequently, the learning environment has to be controlled in order to create appropriate stimulus-response associations (Staub and Stern, 2002), with teachers required to explain correct solutions and provide clear and structured instruction (OECD, 2009).

Constructivist teaching beliefs, on the other hand, describe a student-centered approach to teaching, in which teachers "proactively initiate, prompt, and assist students' constructions" of knowledge (Staub and Stern, 2002, p. 345). Such constructivist approaches stress the need to promote problem-solving and exploratory learning (Handal, 2003), with teachers enabling students to play an active in role in the classroom (OECD, 2009).

Research has shown that most teachers beliefs about these teaching models are not black-and-white. That is to say that they mostly do not assume that merely constructivist or merely transmissive teaching is the most successful option and the other is detrimental. Teachers therefore do not situate transmissive and constructivist beliefs about teaching and learning on a unidimensional scale with two contrasting poles (e.g., Hermans et al., 2008). Instead, teachers may exhibit both highly constructivist and highly transmissive beliefs-i.e., hold favorable beliefs toward student-centered and toward teachercentered instruction-depending on the context in which these beliefs are activated (e.g., Snider and Roehl, 2007; Fives and Buehl, 2012).

The TALIS study (OECD, 2009) indicated that teachers in secondary education show higher constructivist than transmissive beliefs. In the same publication, the authors found associations between beliefs and respective instructional practices when controlling for background characteristics and other beliefs. These findings were particular prominent for constructivist beliefs, which were associated with studentoriented practices. In contrast, structuring practices were not persistently and strongly related to teachers' transmissive beliefs.

From a theoretical perspective, possessing beliefs about constructivist as well as transmissive teaching could be more appropriate in inclusive settings. Constructivist and studentcentered approaches are more focused on addressing students' individual profiles and might therefore enable teachers to more effectively address heterogeneous classrooms (Akpan and Beard, 2016). In addition, constructivist teaching aims to relate more strongly to real-life problems and therefore to be more accessible for students with learning disabilities, "because of their difficulty in generalizing from the classroom to other settings" (Steele, 2005, p. 2). At the same time, transmissive approaches have proven to be particularly effective (compared to constructivist approaches) when addressing students with learning difficulties (Kroesbergen, 2004). Swanson et al. (2014) have also highlighted that transmissive teaching approaches, e.g., explicit instruction and strategy instruction, are the most effective instructional approaches when targeting students with learning disabilities.

\section{Considering Social Desirability and Automaticity When Examining the Relationship Between Attitudes Toward Inclusion and Beliefs About Teaching and Learning}

Despite the presumed association between attitudes toward inclusion and beliefs about teaching and learning, there are only a few studies to date (Silverman, 2007; Sheehy et al., 2019) that have investigated this relationship. In addition, the existing work only considers explicit reports about attitudes and beliefs.

These explicit reports frequently aim to measure attitudes toward inclusion (e.g., de Boer et al., 2011; Saloviita, 2015) as well as to measure beliefs about the nature of teaching and learning (e.g., Chan and Elliott, 2004; Silverman, 2007; Sheehy et al., 2019). However, as highlighted by Lüke and Grosche (2018a,b), explicit reports about attitudes and beliefs might be prone to social desirability bias, leading to study participants giving more positive, socially desirable accounts of their attitudes and beliefs.

In line with this assumption, Lüke and Grosche (2018a) have shown that the presumed attitudes toward inclusion of the organization conducting a given survey has a strong influence on the reported attitudes of the participants, even outperforming well-established predictors of attitudes toward inclusion. This finding emphasizes the difficulty for researchers when measuring the unbiased attitudes of study participants. Similar assumptions can be made regarding the measurement of beliefs about teaching and learning. 
In addition to this, and in accordance with the ideas of dual-process theories, mental processes can be further differentiated as being either automatic (unconscious) or controlled (conscious) (e.g., Gawronski and Bodenhausen, 2011; Gawronski and Creighton, 2013). Whilst explicit measures of attitudes (such as questionnaires) are effective at measuring controlled processes, and might consequently serve as good predictors for behavior in specific situations, automated mental processes have been neglected in past research. Consequently, results on the associations between explicit attitudes and beliefs may be of particular relevance for predicting behavior in controlled situations, but they may lack validity when predicting behavior in situations that entail limited cognitive resources and time. Several researchers have thus argued that applying a multi-method approach to the assessment of attitudes/beliefs and underlying spontaneous associations may be a more holistic approach to describing teachers' attitudes (Lautenbach and Antoniewicz, 2018; Lüke and Grosche, 2018b). In accordance with this approach, research is increasingly focused on capturing automatic evaluations toward inclusion and types of special educational needs (Markova et al., 2016; Krischler and Pit-ten Cate, 2018, 2019).

Automatic evaluations are frequently assessed using measures based on reaction time (for an overview see Gawronski and De Houwer, 2013) that avoid the need for participants to consciously reflect on their own convictions about a subject. These measures employ computerized tools that indirectly assess automatic evaluations by recording the speed and accuracy of reactions to stimuli.

One prominent reaction-time based measure is the Implicit Association Test (IAT; Greenwald et al., 1998). At the core of the IAT is a sorting task with two categories: a target concept (e.g., "inclusion") and an attribute category (e.g., "good"). Resulting scores are interpreted as the strength of positive associations (i.e., automatic evaluations) with the respective target concept (e.g., inclusion). The two target categories often include pairs of opposites (e.g., "young" and "old"), to which presented stimuli have to be assigned in changing task blocks. Thus, the traditional IAT yields a relative score of preferring or disliking one concept over another.

When measuring automatic evaluations toward inclusion only one target concept is available, and no clearly defined comparison category can be ascribed. Similarly, transmissive and constructivist attitudes do not depict contrary extremes on a onedimensional scale. Indeed, as outlined above, people may well hold positive positions on both constructivist and transmissive beliefs and attitudes about learning and teaching at the same time. Therefore, traditional IAT was not applicable for the purposes of this study.

Responding to this limitation, single-target IAT (ST-IAT; Wigboldus et al., 2006) represents another approach to measure automatic evaluations toward one specific attitude object. The ST-IAT focuses on the target category of interest (e.g., "inclusion") and measures the associative strength with the evaluative attribute categories ("good" or "bad"). Therefore, the resulting data represent the absolute (positive or negative) automatic evaluations of the target category, as no comparison to a reference concept is made (Lüke and Grosche, 2018b). Such an approach may be promising when investigating the relation of teachers' attitudes and beliefs about teaching and learning.

\section{Objectives of the Current Study}

To date, few studies have examined the relationship between teachers' attitudes toward inclusion and their beliefs about teaching and learning. In addition to this, there is no study that has aimed to capture teachers' attitudes and beliefs multidimensionally nor taken automatic evaluations into account. Consequently, no study has tried to address different explicit and implicit measures of attitudes nor overcome possible influences of social desirability (e.g., Silverman, 2007; Sheehy et al., 2019). Examining this relationship may well be relevant as implicit measures of attitudes and beliefs may be better predictors of behavior in specific situations that entail less volitional control. In this sense, day-to-day teaching practices not only comprise controllable situations but also unforeseeable and spontaneous situations. Emphasizing attitudes and beliefs relevant to such situations could thus contribute to a more complete understanding of teachers' attitudes and beliefs.

With regard to these desiderata, the aim of the study at hand was to examine the relations between attitudes toward inclusion and beliefs about teaching and learning. In addition, we wanted to focus on possible differences in patterns of relations, when differentiating between explicit attitudes/beliefs and automatic evaluations. In this context, the following research questions were addressed:

(1) To what extent are explicit attitudes toward inclusion, beliefs about teaching, and learning and the respective automatic evaluations associated?

As discussed above, attitudes toward inclusion as well as transmissive and constructivist beliefs about teaching and learning could be prone to bias by social desirability. Moreover, explicit measures and automatic evaluations do not necessarily depict the same construct.

(2) Is there a difference between, on the one hand, the relation of explicit attitudes toward inclusion and beliefs about transmissive/constructivist teaching and, on the other, the relation of respective automatic evaluations?

Regarding the second research question, we assume that (a) attitudes toward inclusion are more closely associated with constructivist than with explicit transmissive attitudes toward teaching and learning. This would be in line with the results reported by Sheehy et al. (2019). At the same time, previous results might have been influenced by social desirability bias. We also hypothesize that (b) automatic evaluations toward inclusion are closely related to both automatic evaluations toward transmissive and constructivist teaching and learning. This goes hand in hand with the described theoretical assumptions of interrelations between constructivist as well as transmissive teaching and attitudes toward inclusion. The application of constructivist as well as transmissive teaching could be more appropriate in inclusive settings and might lead to associations between these constructs. 
TABLE 1 | List of Stimuli of the Target Concepts in the ST-IAT.

\begin{tabular}{|c|c|c|c|c|}
\hline ST-IAT transmissive teaching & ST-IAT constructivist teaching & ST-IAT inclusion ${ }^{a}$ & Positive & Negative \\
\hline Teacher-centered & Problem-oriented & School for all & Different positive emoticons & Different negative emoticons \\
\hline Predefined & Independent & UN-convention & & \\
\hline Definitions & Reflect & Participation & & \\
\hline Review & Self-regulated & Disability & & \\
\hline
\end{tabular}

a Stimuli of the ST-IAT Inclusion originate from Lüke and Grosche (2018b).

\section{METHOD}

\section{Participants and Data Collection}

We collected the data of 197 teacher students $(22.7 \pm 5.9$ years; $85 \%$ female) at a German university. All participants were contacted during a mandatory university lecture on inclusive education. Participation in the study was anonymous and voluntary. All participants were training to become primary school teachers and were in the first semester of their studies. Almost a third of all participating students had participated in a study program with a focus on inclusionrelated topics. The data collection was carried out by three student assistants.

\section{Procedure}

As, according to the local institutional requirements, ethical review and approval of studies is only necessary when conducting an intervention study, or a project with an increased risk of physical and/or mental harm, or a study, where the collection of written and informed consent is not directly applicable (e.g., in children), no ethical approval was required. Data collection took part in small group settings in a learning lab. A maximum of four students participated in each session. To minimize disturbance from other participants, headphones were used and the workspaces were separated by partition walls. Each session was accompanied by a trained student assistant, who instructed the participants and ensured a smooth data collection. Before data collection, all students were informed that participation in the study was voluntary and about their right to withdraw from the study once participation had begun. Students were also informed that non-participation or withdrawal from participation would not have any negative consequences. In the first stage, participants were asked to fill out the online survey, comprising the explicit measures of attitudes toward inclusion as well as transmissive and constructivist attitudes toward teaching and learning. Participants then completed three individual ST-IATs measuring: firstly, automatic evaluations toward inclusion; secondly, automatic evaluations toward transmissive teaching and learning; and thirdly, automatic evaluations toward constructivist teaching and learning. The sequence of the presentation of the three ST-IATs was varied and balanced to overcome potential sequence effects. The ST-IATs were presented using the Software Inquisit Lab 5 (Millisecond Software, 2019).

\section{Measures \\ Explicit Attitudes Toward Inclusion}

Teachers' explicit attitudes toward inclusion were measured using a 14-item scale (PREIS; Lüke and Grosche, 2017; e.g., "I think that the implementation of inclusive education will have a positive influence on our society."). Participants had to answer the items on a 5 -point Likert scale ( $1=$ "disagree" to $5=$ "agree"). Internal consistency was very high (Cronbach's $\alpha=0.89$ ).

\section{Explicit Transmissive and Constructivist Beliefs About Teaching and Learning}

Explicit beliefs about teaching and learning were measured using the scales transmission and construction from the questionnaire for four teachers' beliefs (Q4TB) developed by Schlichter (2012). Explicit transmissive beliefs were assessed using 10 items (e.g., "To me, teaching means presenting lesson content in a way that students can comprehend well"). Constructivist explicit attitudes were assessed using 11 items (e.g., "To me, teaching means creating a learning environment in which students can follow their individual learning paths"). Participants had to answer the items on a 5 -point Likert scale $(1=$ "strongly disagree" to $5=$ "strongly agree"). Internal consistency was acceptable to good (Cronbach's $\alpha=0.79$ for transmissive beliefs and $\alpha=0.83$ for constructivist beliefs.

\section{Automatic Evaluations}

Automatic evaluations toward inclusion as well as transmissive and constructivist teaching and learning were assessed with three individual ST-IATs. Each ST-IAT followed the same block structure in which participants were first familiarized with the categorization task before working on the critical trials. The first block contained 20 stimuli (i.e., "smileys" and "frownys") that either had to be classified as "good" or "bad" (i.e., attribute categories, see Brand and Antoniewicz, 2016) by pressing the "E" or "I" key on a standard German QWERTZ keyboard. The stimulus remained in the middle of the screen until the participant had categorized it. The same attribute categories and attribute stimuli were used in all three ST-IATs. In the next blocks, target (e.g., "inclusion") and attribute categories (i.e., "good" and "bad") were linked. Stimuli had to be assigned to one of two response categories that combined, for example, "inclusion" with either "good" or "bad" (i.e., inclusion + good vs. bad/inclusion + bad vs. good). Twenty practice trials per combination preceded the two critical blocks that consisted of 40 trials each. Table 1 lists all target and attribute stimuli of the three respective ST-IATs. 


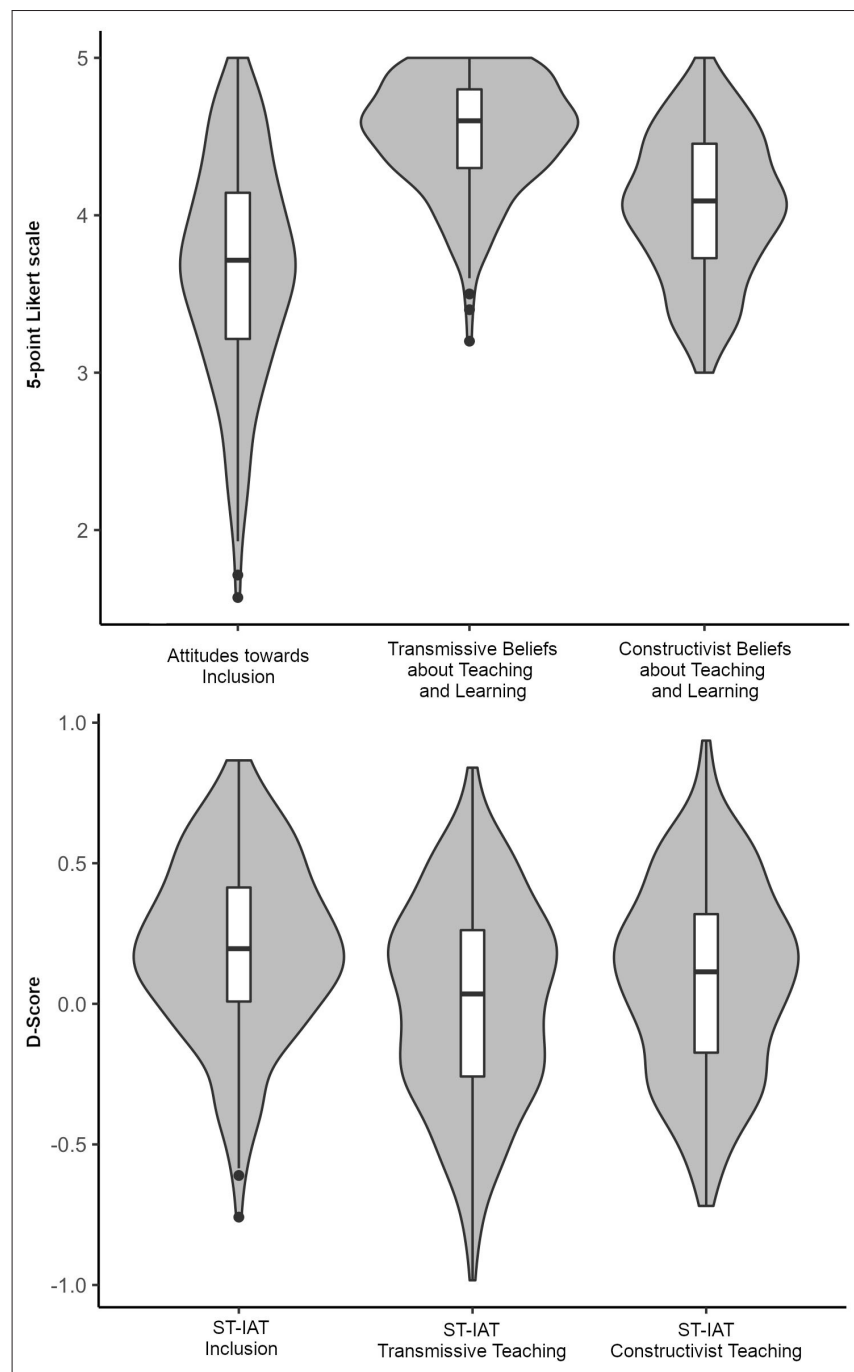

FIGURE 1 | Distribution and probability density of explicit measures and automatic evaluations toward inclusion and transmissive and constructivist teaching and learning.

The intertrial interval was $250 \mathrm{~ms}$. All participants were asked to categorize the stimuli as quickly and accurately as possible. The underlying concept of the ST-IAT is that people respond more quickly when strongly associated concepts share the same response key. ST-IAT results are typically reported as betweenblocks difference scores (D-Score, see Greenwald et al., 2003) that can range from -2 to +2 . A positive $\mathrm{D}$-Score represents more positive automatic evaluations with the target category.

\section{Statistical Analyses}

Multiple regression analyses using a maximum-likelihood estimation method were carried out to gain insights into the relationship between explicit attitudes/beliefs and automatic evaluations toward inclusion, as well as transmissive and constructivist teaching and learning, and thus aimed to answer the first research question.

In a similar vein, multiple regression analyses were carried out to analyse the relationships between attitudes toward inclusion and constructivist and transmissive attitudes about learning and teaching, as well as the relationships between automatic evaluations of inclusion and automatic evaluations of constructivist and transmissive teaching and learning, thus answering the second research question.

In the first model, the score in the explicit measure of attitudes toward inclusion was regressed based on the scores in the explicit measures of transmissive and constructivist beliefs about teaching and learning. In the second model, the Dscore of the ST-IAT inclusion was regressed on the D-score in the ST-IAT transmissive beliefs and the ST-IAT constructive beliefs about teaching and learning. The items study-related inclusion emphasis, semester, and gender were included as control variables. Standardized regression coefficients $(\beta)$ were used to compare the relative importance of the predictors in the model. Adjusted $\mathrm{R}^{2}$ was used to describe the explained variance of the models. The analyses were carried out using the software RStudio (RStudio Team, 2019).

\section{RESULTS}

\section{Descriptive Statistics}

The participants' distribution of attitudes, beliefs, and automatic evaluations are presented in Figure 1. In general, the participants showed very positive beliefs about transmissive teaching: $\mathrm{M}(\mathrm{SD})=4.50 \quad(0.36)$. Explicit constructivist beliefs about teaching and learning were similarly positive: $\mathrm{M}(\mathrm{SD})=4.05(0.36)$. Paired $t$-tests revealed that these differences between constructivist and transmissive beliefs were statistically significant $(t=12.54 ; p<0.001)$. In comparison, participants showed lower but still positive levels of attitudes toward inclusion: $M(S D)=3.71(0.72)$. With regard to automatic evaluations toward inclusion, the D-score indicated a positive tendency: $\mathrm{M}(\mathrm{SD})=0.20$ (0.32). In contrast, the D-score for constructivist teaching was ambivalent: $\mathrm{M}(\mathrm{SD})=0.09(0.34)$, as well as the D-score for transmissive teaching: $M(S D)=0.01$ (0.36). Paired $t$ tests revealed that these differences between constructivist and transmissive beliefs were statistically significant: $t=2.51 ; p<0.05$.

\section{Research Question 1}

The associations of explicit attitudes toward inclusion and constructivist/transmissive beliefs about teaching and learning through automatic evaluations were examined using multiple regression analyses (see Table 2). When controlling for demographics (gender, study programm, study semester), the association between explicit attitudes toward inclusion and automatic evaluations were fairly low but significant, $\beta=$ $0.14, p=0.04$. We found similiar results for the association of explicit beliefs about transmissive teaching and learning as well as automatic evaluations toward transmissive teaching. When controlling for demographics the two constructs were positively related, $\beta=0.16, p=0.02$. In contrast, explicit attitudes of constructivist beliefs about teaching and learning and respective automatic evaluations were not signficantly related, $\beta=0.07$, $p=0.29$. 
TABLE 2 | Predicting explicit attitudes toward inclusion and beliefs about teaching and learning by automatic evaluations (ST-IAT D-Score).

\begin{tabular}{|c|c|c|c|c|c|c|c|c|c|}
\hline & \multicolumn{3}{|c|}{ Attitudes toward inclusion } & \multicolumn{3}{|c|}{ Transmissive beliefs } & \multicolumn{3}{|c|}{ Constructivist beliefs } \\
\hline ST-IAT D-score ${ }^{a}$ & 0.14 & {$[0.01 ; 0.27]$} & 0.037 & 0.16 & {$[0.02 ; 0.30]$} & 0.024 & 0.07 & {$[-0.06 ; 0.21]$} & 0.298 \\
\hline Study program ${ }^{b}$ & 0.72 & {$[0.42 ; 1.01]$} & $<0.001$ & 0.02 & {$[-0.29 ; 0.33]$} & 0.902 & 0.21 & {$[-0.09 ; 0.50]$} & 0.178 \\
\hline Study semester & 0.16 & {$[0.03 ; 0.30]$} & 0.018 & 0.02 & {$[-0.12 ; 0.16]$} & 0.778 & 0.14 & {$[-0.00 ; 0.28]$} & 0.052 \\
\hline Adj. $R^{2}$ & \multicolumn{3}{|c|}{0.12} & \multicolumn{3}{|c|}{0.05} & \multicolumn{3}{|c|}{0.07} \\
\hline
\end{tabular}

$N=197$.

a D-Scores refer to the ST-IAT of the respective construct.

bStudy program: 1 = inclusive education.

$c_{1}=$ female

TABLE 3 | Predicting student teachers' explicit attitudes toward inclusion from their explicit transmissive and constructivist beliefs and demographics.

\begin{tabular}{lccc}
\hline & $\boldsymbol{\beta}$ & $\boldsymbol{C l}$ & $\boldsymbol{p}$ \\
\hline Intercept & -0.18 & {$[-0.53 ; 0.17]$} & 0.314 \\
Transmissive teaching & -0.09 & {$[-0.22 ; 0.05]$} & 0.205 \\
Constructivist teaching & 0.31 & {$[0.17 ; 0.44]$} & $<0.001$ \\
Study program $^{\mathrm{a}}$ & 0.65 & {$[0.37 ; 0.94]$} & $<0.001$ \\
Study semester $^{\text {Gender }}$ & 0.11 & {$[-0.02 ; 0.24]$} & 0.089 \\
& -0.02 & {$[-0.39 ; 0.34]$} & 0.898 \\
\hline
\end{tabular}

$N=197, R^{2} / R^{2}$ adjusted $=0.197 / 0.176 ; F_{(5,191)}=9.352, p<0.01$.

a Study program: 1 = inclusive education.

${ }^{b_{1}}=$ female

\section{Research Question 2}

To examine differences between, on the one hand, the relationship between attitudes toward inclusion and transmissive/constructivist beliefs and, on the other, the relationship between automatic evaluations toward inclusion and automatic evaluations toward transmissive/constructivist teaching and learning, we ran two separate regression models focused on explicit attitudes (see Table 3) and automatic evaluations (see Table 4).

The first regression model (Table 3) showed that explicit attitudes toward inclusion are associated with explicit constructivist beliefs about teaching and learning: $\beta=0.31$, $p<0.001$. Thus, students who agreed more with constructivist teaching had more positive attitudes toward inclusion. In contrast, explicit transmissive beliefs about teaching and learning did not statistically predict explicit attitudes toward inclusion at a significant level: $\beta=-0.09, p=0.205$. Beyond these beliefs, we also found that the fact of whether or not students' training programs had focused on inclusion or not had a statistically significant effect on explicit attitudes toward inclusion, $\beta=$ $0.65, p<0.001$. Thus, students whose study programmes had focused on inclusive education reported more positive attitudes toward inclusion. Students' gender and study duration did not additionally predict attitudes toward inclusion $(p>0.05)$. Our model explained $17.6 \%$ of the variance in students' explicit attitudes toward inclusion.
TABLE 4 | Predicting student teachers' automatic evaluations toward inclusion (D-Score) from their automatic evaluations toward transmissive and constructivist teaching and learning and demographics.

\begin{tabular}{lccr}
\hline & $\boldsymbol{\beta}$ & $\boldsymbol{C l}$ & \multicolumn{1}{c}{$\boldsymbol{p}$} \\
\hline Intercept & 0.05 & {$[-0.30 ; 0.40]$} & 0.764 \\
Transmissive teaching $(D-S c o r e)$ & 0.25 & {$[0.12 ; 0.39]$} & $<0.001$ \\
Constructivist teaching (D-Score) $^{2}$ & 0.26 & {$[0.13 ; 0.39]$} & $<0.001$ \\
Study program $^{\text {a }}$ & -0.03 & {$[-0.32 ; 0.26]$} & 0.845 \\
Study semester $_{\text {Gender }}^{\text {b }}$ & -0.04 & {$[-0.17 ; 0.09]$} & 0.562 \\
& -0.05 & {$[-0.42 ; 0.31]$} & 0.775 \\
\hline
\end{tabular}

$N=197, R^{2} / R^{2}$ adjusted $=0.157 / 0.135 ; F_{(5,191)}=7.105, p<0.01$.

aStudy program: 1 = inclusive education.

$b_{1}=$ female.

Our second regression model (Table 4) showed that students' automatic evaluations of inclusion were statistically significantly associated with their automatic evaluations of transmissive ( $\beta=$ $0.25, p<0.001)$ and of constructivist teaching and learning $(\beta=$ $0.26, p<0.001)$. Thus, students who more positively evaluated transmissive teaching had more positive automatic evaluations of inclusion. Similarly, students who evaluated constructivist teaching more positively also had more positive automatic evaluations of inclusion. We found no statistically significant effects of demographics or study focus on automatic evaluations toward inclusion $(p>0.05)$. Our model explained $13.5 \%$ of the variance in students' automatic evaluations of inclusion.

\section{DISCUSSION}

The present study aimed to provide insights into the association between attitudes toward inclusion and beliefs about teaching and learning. There was thus a special focus on describing differences in these associations when looking at explicit attitudes and beliefs compared to automatic evaluations. In general, it became clear that the participants had fairly positive attitudes toward inclusion as well as positive transmissive and constructivist beliefs about teaching and learning. At the same time, explicit attitudes/beliefs and automatic evaluations were not necessarily interrelated. There were no significant associations 
between explicit beliefs and automatic evaluations, especially when focusing on constructivist beliefs about teaching and learning. One possible explanation for this finding might be that explicit measures are in part influenced by a social desirability bias (Lüke and Grosche, 2018a).

Although both measures address similar constructs, the explicit participants' responses might be biased by the perceived social desirability of inclusive teaching, as inclusive education is a topic that has been discussed in the public realm. Analogously, constructivist teaching methods might be regarded as being a fashionable approach to teaching that emphasizes students' individuality. If social desirability leads to biased results, implicit measures (such as automatic evaluations) of both constructs might therefore represent a way of overcoming potentially biased self-reporting.

To add to this, the observed differences between explicit attitudes/beliefs and automatic evaluations might be due to depicting different facets of the same attitude object. As outlined above, explicit measures, like questionnaires, may be appropriate for gaining insights into conscious mental processes and cognitive components of attitudes. The questionnaires applied in the present study focused on cognitive components of attitudes (e.g., thoughts and knowledge), whilst the ST-IATs employed were used to measure automated and affective components (e.g., positive or negative "gut feelings") of attitude objects (Brand and Antoniewicz, 2016; Krischler and Pit-ten Cate, 2019). Therefore, both facets are not necessarily interrelated and might be of relevance under different conditions. Gawronski and Creighton (2013) argue that explicit measures "reveal the same automatically activated attitudes that are reflected in implicit measures" (p. 287), but at the same time comprise evaluations and inferences about the current situation. Such evaluations and inferences require sufficient available cognitive resources and time.

For this reason, automatic evaluations can be seen as being of particular relevance in demanding situations with limited time and cognitive resources (e.g., responding to classroom disturbances). Attitudes and beliefs might be better predictors of teachers' behavior in controlled situations with more available time to reflect (e.g., preparing lessons, developing curricula; Fazio, 1990; Krischler and Pit-ten Cate, 2019). In daily practice, both facets might influence teachers' behaviors, depending on the respective setting and situation.

It is also apparent that the patterns of associations between attitudes toward inclusion and participants' beliefs about teaching and learning differed when considering either explicit attitudes and beliefs or corresponding automatic evaluations. With regard to explicit measures, transmissive teaching beliefs were not associated with positive attitudes toward inclusion. In contrast, higher constructivist beliefs led to more positive attitudes toward inclusion. These results support previous studies examining possible associations between beliefs about teaching and learning and attitudes toward inclusion (Silverman, 2007; Sheehy et al., 2019). Participants with stronger constructivist beliefs might have an understanding of teaching, which sees learning as an individual process. This goes hand in hand with the understanding of heterogeneity as a basic characteristic of their students and the feeling of being better prepared for inclusive education. Therefore, stronger constructivist beliefs might go hand in hand with more positive attitudes toward inclusion.

In contrast, a different pattern of results was revealed when we looked at automatic evaluation. We found that both automatic evaluations of transmissive and of constructivist teaching and learning explained automatic evaluations of inclusion to a very similar degree. Thus, no differentiation can be made about whether or not stronger constructivist or transmissive automatic evaluations go hand in hand with more positive automatic evaluations toward inclusion. This research therefore only partially supports the assumptions of Sheehy et al. (2019), who argued that their insights challenged beliefs "in a pedagogic eclecticism" (p. 51). With regard to these results, positive automatic evaluations toward inclusion as well as transmissive and constructivist teaching are not contradictory. However, further interpretations of these findings with regard to possible causal explanations are difficult, as only cross-sectional data were analyzed. At the same time, the explained variance $\left(R^{2}\right)$ in both models is fairly low. This indicates that, when explaining attitudes toward inclusion, additional factors affecting preservice teachers' attitudes should be considered. As partially indicated in our results, study program might be such a factor. Previous research additionally highlighted the relevance of the types of special educational needs related to inclusive teaching as an important predictor. Moreover, teaching experiences as well as experience of contact might contribute to attitudes toward inclusion (e.g., Avramidis and Norwich, 2002).

In addition to differences between explicit and implicit measures, the predictive patterns share some similarities. Especially, the predictive effect of constructive beliefs of teaching and learning on pre-service teachers' attitudes toward inclusion is comparable when focusing explicit or implicit measures. Both analyses therefore indicate the relevance of constructivist beliefs for attitudes toward inclusion. A potential interpretation of this finding might be that student teachers perceive studentcentered teaching approaches to be more appropriate for inclusive teaching. The relevance of constructivist beliefs for inclusive teaching can thereby be supported by recent research. Fischer and Hänze (2020) indicate that university teachers' higher constructivist beliefs are associated with observed higher student involvement, rapport and the clarity of instruction. Involvement of all students and rapport between teachers and students might be seen as key characteristics of inclusive learning environments. Moreover, Darmawan et al. (2020) relates beliefs about selfregulated learning and constructive teaching. Student teachers with higher constructivist beliefs might also see self-regulated learning as a means of addressing students with disabilities, who are often characterized by self-regulation difficulties (e.g., Korinek and deFur, 2016).

At the same time, these findings need to be discussed with caution. Fischer and Hänze (2020) did not find any significant association between reported constructivist beliefs and the actual observed use of student-activating teaching methods. Therefore, holding positive beliefs about constructivist teaching might not necessarily lead to the application of student-centered teaching methods. This goes in hand with previous findings (EbertMay et al., 2011; Assen et al., 2016), even describing a use of transmissive teaching methods despite holding constructivist 
beliefs about teaching. Moreover, Darmawan et al. (2020) highlighted that some student teachers hold constructivist and transmissive beliefs about teaching at the same time. Post-hoc correlational analysis of our data indicated that transmissive and constructivist beliefs were only weakly associated. However, some individuals might exhibit similar levels of transmissive and constructivist beliefs.

Our insights indicate that, depending on the nature of information under consideration, different pattern of results are apparent. This seems to be of particular relevance, as the majority of previous research and most of the assumptions about explanatory models of attitudes toward inclusion are based on studies that rely on explicit reports. Just relying on either implicit or explicit information may lead to erroneous interpretations and assumptions about the development of attitudes toward inclusion or beliefs about teaching and learning. In addition, studies should consider in which real-world situations the findings are of relevance. In this context, it would be of particular interest to do more work on the relationship between attitudes and beliefs, subsequent automatic evaluations, and teachers' behaviors in daily practice. With regard to the possibility that explicit measures and automatic evaluations depict different facets of attitudes (Gawronski and Creighton, 2013), teachers' behaviors in different settings (controlled vs. uncontrolled) should be observed and related to both measures.

\section{Limitations}

The present study has a number of limitations. Firstly, the sample in this study only comprised teaching students. We can therefore not generalize our findings to the attitudes, beliefs, and automatic evaluations of experienced teachers. Future research should thus aim to replicate this study with in-service teachers. Secondly, this study only comprised cross-sectional data. Therefore, causal interference about the relation of attitudes toward inclusion and beliefs about learning is not possible. Further studies with a longitudinal or experimental design are necessary to address this deficit. Thirdly, we did not assess teachers' actual behavior in the classroom. Future research into the interplay between automatic evaluations, explicit reports, and actual classroom behavior could be promising way of filling this gap. Lastly, we discussed the differences between explicit and implicit measures with regard to a possible influence of social desirability. However, we did not control social desirability in the analysis. Additional replication studies should therefore include a social desirability scale in the survey design to control this variable in their data analysis.

\section{CONCLUSIONS}

In this study, we were not able to describe any overarching pattern in the relationship between attitudes toward inclusion, beliefs about teaching and learning, and automatic evaluations. Instead, we were able to show that the relationship differs depending on the type of measures used (i.e., explicit self-reports vs. automatic evaluations).
Explicit attitudes/beliefs and automatic evaluations may predict behavior in different situations. Relying solely on one information source might lead to erroneous interpretations and assumptions. Instead, it would seem judicious to use multi-methodological approaches in the measurement of attitudes toward inclusion. In summary, the present study sheds light on the relevance of student teachers' beliefs and automatic evaluations about teaching and learning in explaining positive attitudes and automatic evaluations toward inclusion.

Additional research should examine the associations between explicit attitudes, automatic evaluations, and observed behavior. For instance, questionnaire and implicit measures should be complemented by observer ratings or student ratings of the instructional settings that teachers actually use during their lessons in heterogeneous classrooms. Observing teachers in a range of different instructional settings might also allow deeper insights into the specific situations in which automatic evaluations or explicit attitudes are of relevance for teachers' instructional behavior. In addition, future studies should include child-related and educational environment-related variables in order to illuminate the complex interplay of teachers' attitudes, evaluations and their behavior more broadly. The study at hand provided insights in the potential relevance of both dimensions. With regard to teacher training, additional research is needed on how to address and change student teachers' automatic evaluations. Ideas on how to design and select such interventions might be found in concepts on how to address implicit bias and stereotype threat in education (e.g., debiasing; Godsil et al., 2014). The current study indicated that students enrolled in a study program with a specific focus on inclusive education hold more positive explicit attitudes toward inclusion than students in general teacher training programs do. However, longitudinal research is needed to examine more closely, whether these differences are caused by a self-selection of students with favorable attitudes toward inclusion in these specific study programs or reflect positive outcomes of the study programs. Moreover, we need to identify the specific instructional settings of these study programs that can be effective in fostering student teachers' attitudes and potentially even automatic evaluations toward inclusion.

\section{DATA AVAILABILITY STATEMENT}

The raw data supporting the conclusions of this article will be made available by the authors upon request.

\section{ETHICS STATEMENT}

Ethical review and approval was not required for the study on human participants in accordance with the local legislation and institutional requirements. The patients/participants provided their written informed consent to participate in this study. 


\section{AUTHOR CONTRIBUTIONS}

MB-R outlined the submission and all other authors revised the original version. All authors contributed to this publication and jointly contributed to the data collection.

\section{REFERENCES}

Ajzen, I., and Fishbein, M. (2005). "The influence of attitudes on behavior," in The Handbook of Attitudes, eds D. Albarracin, B. T. Johnson, and M. P. Zanna (New Jersey, NJ: Psychology Press), 173-221.

Akpan, J. P., and Beard, L. A. (2016). Using constructivist teaching strategies to enhance academic outcomes of students with special needs. Univ. J. Educ. Res. 4, 392-398. doi: 10.13189/ujer.2016.040211

Assen, J. H. E., Meijers, F., Otting, H., and Poell, R. F. (2016). Explaining discrepancies between teacher beliefs and teacher interventions in a problembased learning environment: a mixed methods study. Teach. Teach. Educ. 60, 12-23. doi: 10.1016/j.tate.2016.07.022

Avramidis, E., and Norwich, B. (2002). Teachers' attitudes towards integration/inclusion: a review of the literature. Eur. J. Spec. Needs Educ. 17, 129-147. doi: 10.1080/08856250210129056

Brand, R., and Antoniewicz, F. (2016). Affective evaluations of exercising: the role of automatic-reflective evaluation discrepancy. J. Sport Exerc. Psychol. 38, 631-638. doi: 10.1123/jsep.2016-0171

Chan, K.-W., and Elliott, R. G. (2004). Relational analysis of personal epistemology and conceptions about teaching and learning. Teach. Teach. Educ. 20, 817-831. doi: 10.1016/j.tate.2004.09.002

Darmawan, I. G. N., Vosniadou, S., Lawson, M. J., Van Deur, P., and Wyra, M. (2020). The development of an instrument to test pre-service teachers' beliefs consistent and inconsistent with self-regulation theory: coexisting beliefs about self-regulation theory. Br. J. Educ. Psychol. e12345. doi: 10.1111/bjep. 12345

de Boer, A., Pijl, S. J., and Minnaert, A. (2011). Regular primary schoolteachers' attitudes towards inclusive education: a review of the literature. Int. J. Inclusive Educ. 15, 331-353. doi: 10.1080/13603110903030089

Eagly, A. H., and Chaiken, S. (1998). "Attitude structure and function," in The Handbook of Social Psychology, eds D. T. Gilbert, S. T. Fiske, and G. Lindzey (McGraw-Hill), 269-322.

Eagly, A. H., and Chaiken, S. (2007). The advantages of an inclusive definition of attitude. Soc. Cogn. 25, 582-602. doi: 10.1521/soco.2007.25.5.582

Ebert-May, D., Derting, T. L., Hodder, J., Momsen, J. L., Long, T. M., and Jardeleza, S. E. (2011). What we say is not what we do: effective evaluation of faculty professional development programs. BioScience 61, 550-558. doi: 10.1525/bio.2011.61.7.9

Evans, J. St. B. T. (2007). On the resolution of conflict in dual process theories of reasoning. Think. Reason. 13, 321-339. doi: 10.1080/13546780601008825

Evans, J. St. B. T., and Stanovich, K. E. (2013). Dual-process theories of higher cognition: advancing the debate. Perspect. Psychol. Sci. 8, 223-241. doi: $10.1177 / 1745691612460685$

Fazio, R. H. (1990). Multiple processes by which attitudes guide behavior: the mode model as an integrative framework. Adv. Exp. Soc. Psychol. 23, 75-109. doi: 10.1016/S0065-2601(08)60318-4

Fischer, E., and Hänze, M. (2020). How do university teachers' values and beliefs affect their teaching? Educ. Psychol. 40, 296-317. doi: 10.1080/01443410.2019.1675867

Fives, H., and Buehl, M. M. (2012). "Spring cleaning for the "messy" construct of teachers' beliefs: What are they? Which have been examined? What can they tell us?" in APA Educational Psychology Handbook, Vol. 2: Individual Differences and Cultural and Contextual Factors, eds K. R. Harris, S. Graham, T. Urdan, S. Graham, J. M. Royer, and M. Zeidner (Washington, DC: American Psychological Association), 471-499. doi: 10.1037/132 74-019

Fives, H., Lacatena, N., and Gerard, L. (2015). “Teachers' beliefs about teaching (and learning)," in International Handbook of Research on Teachers' Beliefs, eds H. Fives and M. G. Gill (New York, NY; London: Routledge), 249-265.

\section{FUNDING}

The publication of this article was funded by the Open Access Fund of the Leibniz University Hannover.

Gawronski, B., and Bodenhausen, G. V. (2011). The associativepropositional evaluation model. Adv. Exp. Soc. Psychol. 44, 59-127. doi: 10.1016/B978-0-12-385522-0.00002-0

Gawronski, B., and Creighton, L. A. (2013). "Dual process theories," in Oxford Library of Psychology. The Oxford Handbook of Social Cognition, ed D. E. Carlston (Oxford University Press), 282-312.

Gawronski, B., and De Houwer, J. (2013). "Implicit measures in social and personality psychology," in Handbook of Research Methods in Social and Personality Psychology, 2nd Edn., eds H. T. Reis and C. M. Judd (New York, NY: Cambridge University Press), 283-310. doi: 10.1017/CBO9780511996481.016

Godsil, R. D., Tropp, L., Goff, P., and Powell, J. (2014). Addressing implicit bias, racial anxiety, and stereotype threat in education and health care. Sci. Equ. 1:14.

Greenwald, A. G., McGhee, D. E., and Schwartz, J. L. (1998). Measuring individual differences in implicit cognition: the implicit association test. J. Pers. Soc. Psychol. 74:1464.

Greenwald, A. G., Nosek, B. A., and Banaji, M. R. (2003). Understanding and using the implicit association test: I. An improved scoring algorithm. J. Pers. Soc. Psychol. 85, 197-216. doi: 10.1037/0022-3514.85.2.197

Haimovitz, K., and Dweck, C. S. (2017). The origins of children's growth and fixed mindsets: new research and a new proposal. Child Dev. 88, 1849-1859. doi: $10.1111 /$ cdev.12955

Handal, B. (2003). Teachers' mathematical beliefs: a review. Math. Educ. 13, 47-57.

Hermans, R., van Braak, J., and Van Keer, H. (2008). Development of the beliefs about primary education scale: distinguishing a developmental and transmissive dimension. Teach. Teach. Educ. 24, 127-139. doi: 10.1016/j.tate.2006.11.007

Jordan, A., Schwartz, E., and McGhie-Richmond, D. (2009). Preparing teachers for inclusive classrooms. Teach. Teach. Educ. 25, 535-542. doi: 10.1016/j.tate.2009.02.010

Korinek, L., and deFur, S. H. (2016). Supporting student self-regulation to access the general education curriculum. Teach. Except. Child. 48, 232-242. doi: $10.1177 / 0040059915626134$

Krischler, M., and Pit-ten Cate, I. M. (2018). Inclusive education in Luxembourg: implicit and explicit attitudes toward inclusion and students with special educational needs. Int J Inclusive Educ. 24, 597-615. doi: 10.1080/13603116.2018.1474954

Krischler, M., and Pit-ten Cate, I. M. (2019). Pre- and in-service teachers' attitudes toward students with learning difficulties and challenging behavior. Front. Psychol. 10:327. doi: 10.3389/fpsyg.2019.00327

Kroesbergen, E. H. (2004). Effectiveness of explicit and constructivist mathematics instruction for low-achieving students in the Netherlands. Element. School J. 104, 233-251. doi: 10.1086/499751

Lautenbach, F., and Antoniewicz, F. (2018). Ambivalent implicit attitudes towards inclusion in preservice PE teachers: the need for assessing both implicit and explicit attitudes towards inclusion. Teach. Teach. Educ. 72, 24-32. doi: $10.1016 /$ j.tate.2018.01.003

Lüke, T., and Grosche, M. (2017). Professionsunabh?ngige Einstellungsskala zum Inklusiven Schulsystem (PREIS). Licensed under CC-BY-SA. doi: 10.6084/m9.figshare.2245630

Lüke, T., and Grosche, M. (2018a). What do I think about inclusive education? It depends on who is asking. Experimental evidence for a social desirability bias in attitudes towards inclusion. Int. J. Inclusive Educ. 22, 38-53. doi: 10.1080/13603116.2017.1348548

Lüke, T., and Grosche, M. (2018b). Implicitly measuring attitudes towards inclusive education: A new attitude test based on singletarget implicit associations. Eur. J. Spec. Needs Educ. 33, 427-436. doi: 10.1080/08856257.2017.1334432

Markova, M., Pit-Ten Cate, I., Krolak-Schwerdt, S., and Glock, S. (2016). Preserviceteachers' attitudes toward inclusion and toward students with special 
educational needs from different ethnic backgrounds. J. Exp. Educ. 84, 554-578. doi: 10.1080/00220973.2015.1055317

Millisecond Software (2019). Inquisit 5 Lab.

OECD (Ed.) (2009). Creating Effective Teaching and Learning Environments: First Results From TALIS. Paris: OECD.

Pajares, M. F. (1992). Teachers' beliefs and educational research: cleaning up a messy construct. Rev. Educ. Res. 62, 307-332.

RStudio Team (2019). RStudio: Integrated Development for R. RStudio Inc. Available online at: http://www.rstudio.com/

Saloviita, T. (2015). Measuring pre-service teachers' attitudes towards inclusive education: psychometric properties of the TAIS scale. Teach. Teach. Educ. 52, 66-72. doi: $10.1016 /$ j.tate.2015.09.003

Schlichter, N. (2012). Lehrerüberzeugungen zum Lehren und Lernen. Göttingen: Georg-August-Universität.

Sharma, U., and Sokal, L. (2016). Can teachers' self-reported efficacy, concerns, and attitudes toward inclusion scores predict their actual inclusive classroom practices? Australas. J. Spec. Educ. 40, 21-38. doi: 10.1017/jse.2015.14

Sheehy, K., Budiyanto, Kaye, H., and Rofiah, K. (2019). Indonesian teachers' epistemological beliefs and inclusive education. J. Intellect. Disabil. 23, 39-56. doi: $10.1177 / 1744629517717613$

Silverman, J. C. (2007). Epistemological beliefs and attitudes toward inclusion in pre-service teachers. Teach. Educ. Spec. Educ. 30, 42-51. doi: $10.1177 / 088840640703000105$

Snider, V. E., and Roehl, R. (2007). Teachers' beliefs about pedagogy and related issues. Psychol. Schools 44, 873-886. doi: 10.1002/pits.20272

Staub, F. C., and Stern, E. (2002). The nature of teachers' pedagogical content beliefs matters for students' achievement gains: quasi-experimental evidence from elementary mathematics. J. Educ. Psychol. 94, 344-355. doi: $10.1037 / / 0022-0663.94 .2 .344$
Steele, M. M. (2005). Teaching students with learning disabilities: constructivism or behaviorism? Curr. Issues Educ. 8:5.

Swanson, H. L., Harris, K. R., and Graham, S. (Eds.). (2014). Handbook of Learning Disabilities, 2nd Edn. New York, NY: The Guilford Press.

Voss, T., Kleickmann, T., Kunter, M., and Hachfeld, A. (2013). "Mathematics teachers' beliefs," in Cognitive Activation in the Mathematics Classroom and Professional Competence of Teachers, eds M. Kunter, J. Baumert, W. Blum, U. Klusmann, S. Krauss, and M. Neubrand (Boston, MA: Springer US), 249-271. doi: 10.1007/978-1-4614-51495_12

Wigboldus, D. H. J., Holland, R. W., van Knippenberg, A. (2006). Single target implicit associations (Unpublished manuscript). Radboud University, Nijmegen, Netherlands

Woolley, S. L., Benjamin, W.-J. J., and Woolley, A. W. (2004). Construct validity of a self-report measure of teacher beliefs related to constructivist and traditional approaches to teaching and learning. Educ. Psychol. Meas. 64, 319-331. doi: $10.1177 / 0013164403261189$

Conflict of Interest: The authors declare that the research was conducted in the absence of any commercial or financial relationships that could be construed as a potential conflict of interest.

Copyright (๑ 2020 Börnert-Ringleb, Westphal, Zaruba, Gutmann and Vock. This is an open-access article distributed under the terms of the Creative Commons Attribution License (CC BY). The use, distribution or reproduction in other forums is permitted, provided the original author(s) and the copyright owner(s) are credited and that the original publication in this journal is cited, in accordance with accepted academic practice. No use, distribution or reproduction is permitted which does not comply with these terms. 